\title{
Prevalence and pattern of cervical rib, transversomegaly and other vertebral anomalies in normal adult cervical spine in Kumaon region of Uttarakhand, India
}

\author{
Ganesh Singh Dharmshaktu*, Shailendra Singh Bhandari
}

Department of Orthopaedics, Government Medical College, Haldwani, Uttarakhand - 263139, India

Received: 25 March 2016

Revised: 27 March 2016

Accepted: 20 May 2016

*Correspondence:

Dr. Ganesh Singh Dharmshaktu,

E-mail: drganeshortho@gmail.com

Copyright: ( $)$ the author(s), publisher and licensee Medip Academy. This is an open-access article distributed under the terms of the Creative Commons Attribution Non-Commercial License, which permits unrestricted non-commercial use, distribution, and reproduction in any medium, provided the original work is properly cited.

\begin{abstract}
Background: A supernumary rib from seventh cervical vertebra is called cervical rib and is a common anomaly. Its true prevalence is not validated as most of these are asymptomatic thus do not get diagnosed. Its incidence has been reported in several geographic regions and ethnic clusters. Most of the studies rely on radiological data collected from evaluation of chest or neck radiographs of defined numbers.

Methods: A similar study to ascertain its presence and incidence, apart from sexual and morphological pattern is required for Kumaon region of Uttarakhand, India. The present study reports data extracted from study of 1500 radiographs and evaluating them for presence of cervical rib and other abnormalities. Demographic and other relevant details were noted.

Results: Most of the cases were female and almost all cases of cervical rib or transversomegaly were bilateral. $0.8 \%$ and $1.4 \%$ cases were noted for cervical rib and transversomegaly respectively. Apart from it, 4 cases of vertebrae fusion and one case of hemi-vertebra leading to cervical scoliosis was also noted.

Conclusions: The prevalence of cervical rib was comparable to other studies considering the sample size. The calculation of true incidence however will require multi-discipline collaboration and robust data. This study, however, is important for further work in this regard and adds value to existing literature.
\end{abstract}

Keywords: Cervical rib, Block vertebra, Birth defect, Congenital, Transverse process, Human

\section{INTRODUCTION}

Cervical rib may be bony or partially fibrous while attaching itself to the first rib. Its incidence is 0.6 to $0.74 \%$ as per one study with female preponderance and mostly bilateral. ${ }^{1,2}$ In about $10 \%$ cases the presence of rib has been found to be symptomatic. ${ }^{2,3}$ Many studies have reported their incidences in Indian states or places like Lucknow, Chennai and Kashmir. ${ }^{1,4,5}$ The true incidence, however, could not be ascertained fully as not everyone with cervical rib gets radiological assessment. Usual mode of study of its incidence is through evaluation of radiographs as used in various studies. ${ }^{1-5}$ The presence of the anomaly in Kumaon region of Uttarakhand is not attempted and is required for a comprehensive data on its presence and pattern in this geographic region. Apart from it, other deformities like elongated transverse process of seventh vertebra (transversomegaly) or other congenital deformity like block vertebrae or other structural defects are also recorded.

\section{METHODS}

The study incorporated study and evaluation of chest and cervical spine radiographs seen during routine out-patient and those of in-patient. The chest radiograph is a routine 
investigation to be done as pre-anesthetic check-up regarding fitness for surgery, its availability is common. The neck radiographs were taken from out- patient department of Orthopaedics. The study was conducted during the period of July 2014 to February 2015. Only good quality radiographs showing vivid image of cervical spine and relevant area were included in the study. In certain cases MRI (magnetic resonance imaging) or CT (computerized tomogram) scan were also done and assessed. A radiograph showing the presence of cervical rib, elongated transverse process (transversomegaly) or any other defect underwent detailed evaluation. The cases with feature of known syndromes of vertebral fusion like Klippel -Feil syndrome were excluded from the study. The cases appearing like pathological fusion as in cases of ankylosing spondylitis, diffuse idiopathic skeletal hyperostosis were also not included in evaluation. A total of 1500 radiographs 900 cervical spine and 700 chest radiographs were included in the study. Demographic details like name, age, sex, occupation, handedness, laterality and any clinical features associated with the presence of deformity was noted. The cervical rib usually presents as a rib articulating with seventh vertebra through a well-defined joint and if fused, is termed elongated transverse process (especially if it extends beyond first thoracic vertebra margin). The rib should not articulate with manubrium sterni. The radiographs were separately analysed by two authors and final diagnosis was made after consensus of the two. The results were tabulated and analysed to extract the results. The fusion of cervical vertebrae was noted similarly with level and number of vertebra fused. The presence of any other anomaly was noted for the record with name of deformity and location.

\section{RESULTS}

A total of 1500 radiographs showing cervical spine were included in the study. 827 and 676 radiographs were of male and female patients respectively. The well-defined cervical rib was noted in 12 cases $(0.8 \%)$ and transversomegaly in 21 cases $(1.4 \%$ ) (Figure 1 and 2 ). The block vertebra was noted in four cases $(0.26 \%)$ including one with concomitant dorsal spine fusion at multiple levels (Figure 3). The distribution out of gender based radiographs was $0.36 \%$ and $1.33 \%$ for cervical rib in male and female group respectively. The same data for transversomegaly were 0.97 and $1.92 \%$ for male and female respectively. All the cases were found to be asymptomatic for cervical anomalies except one case with cervical scoliosis. The cervical rib and transversomegaly was found to be bilateral in all our cases. Four cases of fusion included two cases with fusion at C2-3 including one case with $\mathrm{C} 2-3$ fusion had concomitant dorsal spine fusion at D1-4 levels) and one each at C3-4 and C5-6. The female cases dominated in combined cervical anomaly cases with 22 out of 38 cases $(57.89 \%)$. Cervical rib and transversomegaly cases were also noted with female preponderances with $75 \%$ and
$61.90 \%$ of total cases of each anomaly. One case of cervical scoliosis due to hemivertebra was also noted (Figure 4). The scoliosis with right side convexity was a result of multiple hemivertebrae.

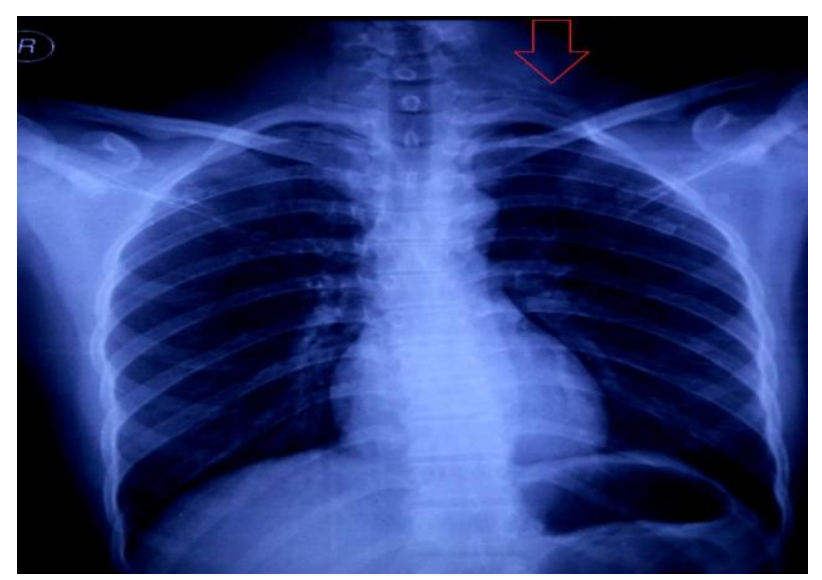

Figure 1: Radiograph showing left sided cervical rib.

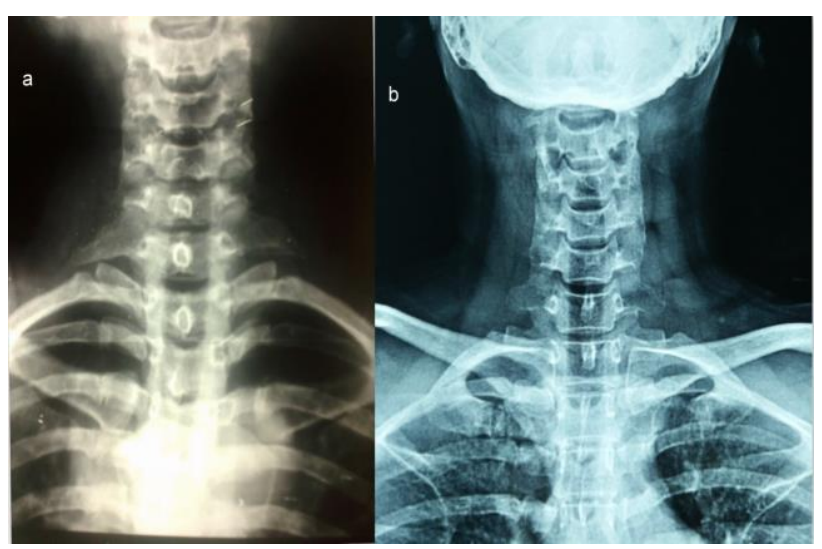

Figure 2 (a \& b): The neck radiograph showing bilateral elongated transverse process.

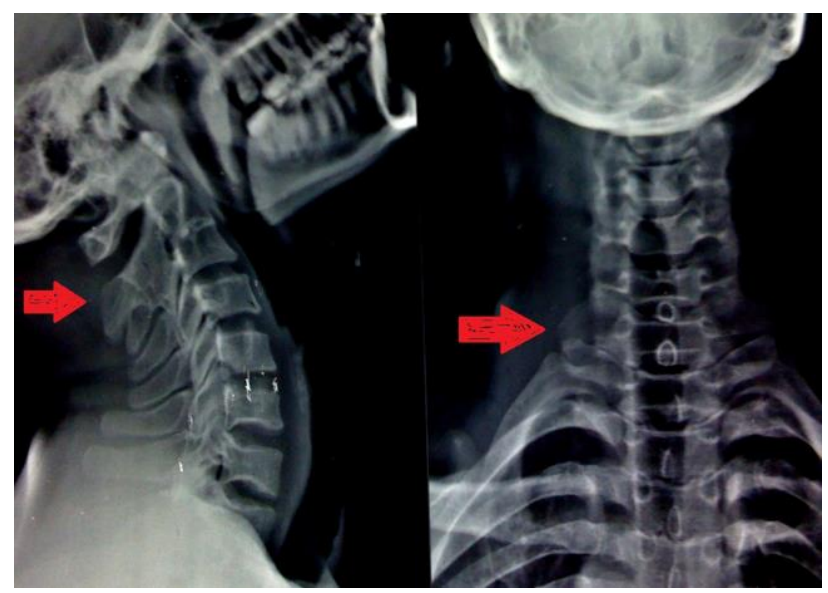

Figure 3: Radiograph showing fusion of cervical veretebrae $\mathrm{C} 2$ and $\mathrm{C} 3$ with bilateral transversomegaly. 


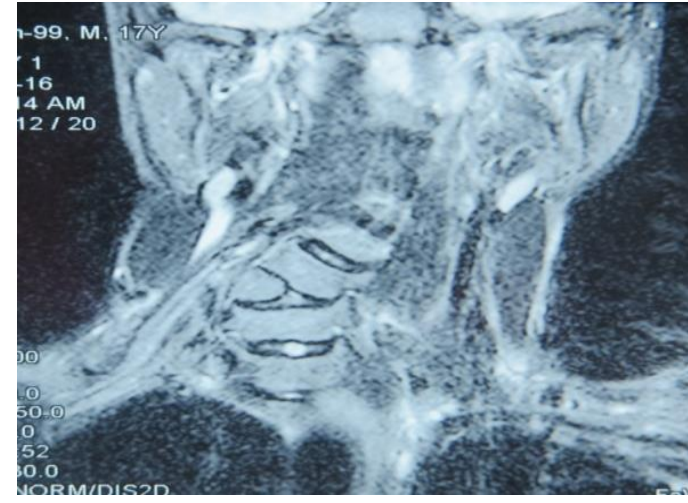

Figure 4: MRI section showing cervical scoliosis with hemivertebra.

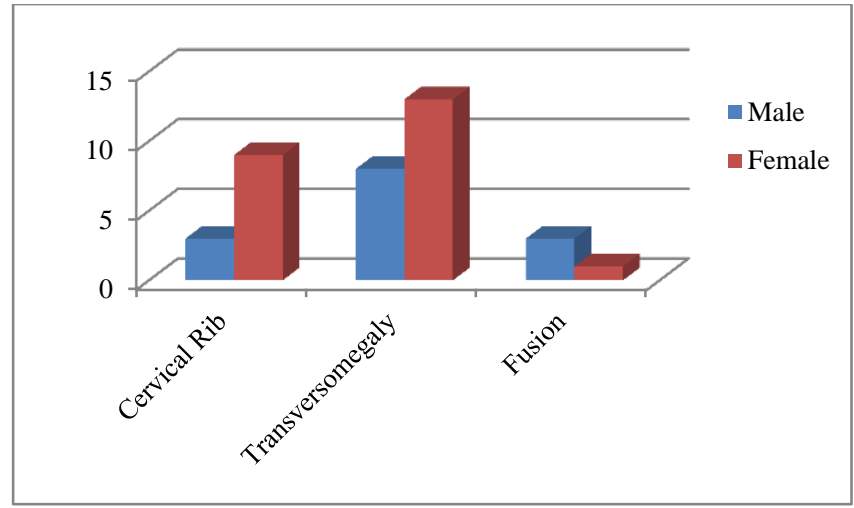

Figure 5: Gender distribution of the study.

Table 1: Table showing key findings of the study.

\begin{tabular}{|lllllllll|}
\hline Age (years) & \multicolumn{2}{c}{ Cervical rib } & \multicolumn{2}{c}{ Transversomegaly } & Fusion & \multicolumn{2}{c|}{ Other anomalies } \\
\hline $\mathbf{2 0 - 2 5}$ & $\mathbf{M}$ & $\mathbf{F}$ & $\mathbf{M}$ & $\mathbf{F}$ & $\mathbf{M}$ & $\mathbf{F}$ & $\mathbf{M}$ & $\mathbf{F}$ \\
\hline $\mathbf{2 6 - 3 0}$ & - & 01 & 01 & - & - & - & 01 & - \\
\hline $\mathbf{3 1 - 3 5}$ & 02 & 05 & 03 & 02 & 02 & - & - & - \\
\hline $\mathbf{3 6 - 4 0}$ & - & 03 & 03 & 07 & 01 & 01 & - & - \\
\hline$>\mathbf{4 0}$ & 01 & - & 01 & 04 & - & - & - & - \\
\hline Total & - & - & - & - & - & - & - & - \\
\hline
\end{tabular}

\section{DISCUSSION}

Most of the previous studies rely upon radiological evaluation of certain number to determine probable prevalence of cervical spine anomalies most notably cervical rib and transversomegaly. The female preponderance and bilaterality which has been found in most of the studies was also noted by us. ${ }^{1-5}$ All cases were asymptomatic except one with cervical scoliosis and all the cases of cervical rib and transversomegaly were bilateral. These findings also collaborate with previous studies. The incidence of cervical spine vertebral fusion in one Indian study has been recorded as $6.25 \%$ as per vertebral specimen study. ${ }^{6}$ Our study noted only four cases $(0.26 \%)$ of cervical spine fusion with commonest at C2-3 level. Previous study about prevalence in Kasmiri population has postulated the probable increased incidence of cervical spine anomalies to race and consanguinity. ${ }^{4,7}$ All of our cases had no issues related to consanguinity. The most common age group of cases was 31-35 years. It is common age for presentation of various disorders of cervical spine like cervical spondylitis and might be reason for increased radiological investigation which in turn adds more cases of any underlying anomalies.

The weakness of the study is a relatively smaller number of data and involvement of a single department. Collaborative study involving relevant other departments that see cervical spine radiographs like ENT, radiology and neurosurgery may lead to comprehensive data pool. Apart from it computerized tomogram and magnetic resonance imaging pool would be adding more cases for more authentic review. An attempt from our side is being taken up for more robust data and its presentation in the future.

Funding: No funding sources Conflict of interest: None declared

Ethical approval: The study was approved by the institutional ethics committee

\section{REFERENCES}

1. Gupta A, Gupta DP, Saxena DK, Gupta RP. Cervical Rib: It's Prevalence in Indian Population around Lucknow (UP). J Anat Soc Ind. 2012;61(2):189-91.

2. Brewin J, Hill M, Ellis $H$. The prevalence of cervical ribs in a London population. Clin Anat. 2009;22:331-36.

3. Roos DB. Congenital anomalies associated with thoracic outlet syndrome: anatomy, symptoms, diagnosis, and treatment. Am J Surg. 1976;132:7718 .

4. Bhat MH, Mir TA, Abdullah I. Prevalence of cervical ribs and elongated transverse processes in Kashmiri population. Int $\mathbf{J}$ Res Med Sci. 2015;3:3763-5. 
5. Venkatesan V, Prabhu KP, Ram Kumar BR, Joseph C. Incidence of Cervical Rib in Chennai Population. World Journal of Medical Sciences. 2014;10(3):250-3.

6. Sharma M, Baidwan S, Jindal AK, Gorea RK. A study of vertebral synostosis and its clinical significance. J Punjab Acad Forensic Med Toxicol. 2013;13(1):20-4.
7. Bokhari RF, Al-Sayyad MJ, Baeesa SS. Prevalence of cervical ribs and elongated transverse processes in Saudi Arabia. Saudi Med J. 2012;33(1):66-9.

Cite this article as: Dharmshaktu GS, Bhandari SS. Prevalence and pattern of cervical rib, transversomegaly and other vertebral anomalies in normal adult cervical spine in Kumaon region of Uttarakhand, India. Int J Res Orthop 2016;2:48-51. 